\title{
Clinicosociodemographic profile of ruptured ectopic pregnancies at a tertiary care centre
}

\author{
Soumya Ranjan Panda, Anjali Rani*, Mahendra Meena
}

Department of Obstetrics and Gynecology, IMS, BHU, Varanasi, Uttar Pradesh, India

Received: 17 February 2017

Accepted: 24 March 2017

\author{
*Correspondence: \\ Dr. Anjali Rani, \\ E-mail: anjaliraniimsbhu@gmail.com
}

Copyright: () the author(s), publisher and licensee Medip Academy. This is an open-access article distributed under the terms of the Creative Commons Attribution Non-Commercial License, which permits unrestricted non-commercial use, distribution, and reproduction in any medium, provided the original work is properly cited.

\section{ABSTRACT}

Background: Rupture of an ectopic pregnancy remains the most dreaded complication of a pregnancy related event and is the commonest cause of maternal mortality in the first trimester of pregnancy. In the developing countries, the maternal death rate among patients admitted with ectopic pregnancy was found to be as high as one in ten. In addition to high risk for mortality, rupture of an ectopic pregnancy could affect future fertility of a woman. The objectives of this study are to analyse the sociodemographic and clinical characteristics and find out the incidence rate and risk factors associated with ruptured ectopic pregnancies in a tertiary care institution.

Methods: This is a retrospective study and was conducted over a period of one year from September 2015 to September 2016 in Department of Obstetrics and Gynecology at Institute of Medical Sciences, BHU, Varanasi, India. It is a tertiary care centre getting referrals not only from nearby cities and hospitals but also from major cities of neighbour states. During this time frame a total of 2601 deliveries have taken place and 57 cases of ruptured ectopic pregnancies were reported. Data were collected in a preconceived format.

Results: Total numbers of vaginal deliveries were 2601 during the study period. Out of which $63(2.42 \%)$ were found to be ectopic pregnancies and $57(1.99 \%)$ were diagnosed as ruptured ectopic pregnancies. Maximum number of patients $(70.17 \%)$ were between 21 and 30 years of age. As far as parity is concerned only $12.29 \%$ of patients were primigravida where as $70.71 \%$ patients were multigravida. Previous history of pelvic inflammatory disease was associated among maximum number of cases i.e $50.87 \%$ of total number of cases. Among other risk factors, previous abortions, previous ectopic pregnancies and history of infertility treatment were the prime ones. Maximum number of patients were from lower and lower middle class socioeconomic status. Ampullary type of Tubal ectopic pregnancies were found to be the commonest ones. Two cornual pregnancies and two ovarian pregnancies were also found in this series. In $85.97 \%$ of patients the amount of hemoperitoneum was found to be more than $500 \mathrm{ml}$.

Conclusions: There is high incidence rate of ectopic pregnancy and low rate of diagnosis before rupture occurs in developing nations as in our scenario. Pelvic inflammatory disease, Maternal education, socioeconomic status, parity and history of subfertilty are the risk factors associated with ruptured ectopic pregnancy. Effective efforts should be taken to encourage the level of education and improve the rate of diagnosis among health care providers before the occurrence of rupture.

Keywords: Ectopic pregnancy, Fallopian tube, Maternal mortality

\section{INTRODUCTION}

Rupture of an ectopic pregnancy remains the most common cause of maternal mortality in the first trimester of pregnancy. ${ }^{1,2}$ Fallopian tubes are the most common site for ectopic pregnancies. Cervix, ovaries, abdomen or the caesarean section scar could be other rare sites that are involved by an ectopic gestation and have an incidence of less than $10 \%$ of the patients. ${ }^{3}$ Risk of rupture remains the most important concern among such patients and the 
management of which is the biggest challenge for obstetricians especially when patients with ruptured ectopic pregnancy with resulting hemoperitoneum and shock are found in the first instance while admission. In the developing countries the maternal death rate among patients admitted with ectopic pregnancy was found to be as high as one in ten. ${ }^{4}$ As far as diagnosis of ruptured ectopics is concerned no particular investigation including serum or urinary beta human chorionic gonadotropin and transvaginal ultrasonography are conclusive and sometimes a surgical approach is required for the differential diagnosis. ${ }^{5,6}$ In addition to high risk for mortality, rupture of an ectopic pregnancy could affect future fertility of a woman.

The objectives of this study are to find out the following factors in a tertiary care institution.

- The incidence of ruptured ectopic pregnancy and its relation to various factors like age group and parity.

- The various risk factors associated with ruptured ectopic pregnancy.

- The various clinical presentation and its outcome in ruptured ectopic pregnancies

\section{METHODS}

This is a retrospective study and was conducted over a period of 1-year from September 2015 to September 2016 in Department of Obstetrics and Gynecology at Institute of Medical Sciences, BHU, Varanasi, India. It is a tertiary care centre getting referrals not only from nearby cities and hospitals but also from major cities of neighbour states. During this time frame a total of 2601 deliveries have taken place and 57 cases of ruptured ectopic pregnancies were reported. Data were collected in a preconceived format. The case sheets of patients with ectopic pregnancy were traced through labor ward registers and operation theatre registers. Information regarding total number of deliveries during study period, details of demographic characteristics, presenting clinical symptoms and signs, parity, use of contraception, diagnostic tool used, detail obstetric history, risk factors for ectopic pregnancy, site of ectopic pregnancy, genital infections, line of management as well as morbidity and morbidity were obtained. Relevant investigations included complete blood picture, blood group, urine pregnancy test (UPT), and ultrasound. Based on thorough evaluation, type of management was decided. Data were collected, tabulated and analyzed. Statistical analysis done by using the statistical software spss version 20.0.

\section{RESULTS}

Total numbers of vaginal deliveries were 2601 during the study period. Out of which $63(2.42 \%)$ were found to be ectopic pregnancies and $57(1.99 \%)$ were diagnosed as ruptured ectopic pregnancies. This is shown in Table 1. In all cases, urine pregnancy was done for provisional diagnosis.
Table 1: Incidence of ruptured ectopic pregnancies.

\begin{tabular}{|lll|}
\hline & \multicolumn{2}{c|}{ Incidence (\%) } \\
\hline Total no. of deliveries & 2601 & \\
\hline $\begin{array}{l}\text { Total no. of ectopic } \\
\text { pregnancies }\end{array}$ & 63 & 2.42 \\
\hline Ruptured ectopic pregnancies & 57 & 1.99 \\
\hline
\end{tabular}

USG helped in diagnosing 44 cases of ectopic pregnancy. Gestational age ranges between 4 and 14 weeks, and the most frequent gestational age was around 6-8 weeks. Right sided ectopic (42/57 patients) were more common than the left side.

Table 2: Socio demographic parameters.

\begin{tabular}{|lll|}
\hline Age (Years) & $\begin{array}{l}\text { No. of patients } \\
(\mathbf{n = 5 7})\end{array}$ & Percent \\
\hline$\leq 20$ & 3 & 5.27 \\
\hline $21-30$ & 40 & 70.17 \\
\hline$>31$ & 14 & 24.56 \\
\hline Parity & & \\
\hline Primigravida & 7 & 12.29 \\
\hline Multigravida & 50 & 87.71 \\
\hline Risk factor & & \\
\hline PID & 29 & 50.87 \\
\hline Abortions & 27 & 47.36 \\
\hline $\begin{array}{l}\text { Previous ectopic } \\
\text { pregnancy }\end{array}$ & 8 & 14.03 \\
\hline H/O infertility treatment & 5 & 8.77 \\
\hline Unidentified & 14 & 24.56 \\
\hline Socio economic status & & \\
\hline High middle class & 3 & 5.26 \\
\hline Low middle class & 17 & 29.82 \\
\hline Lower class & 37 & 64.91 \\
\hline
\end{tabular}

As shown in Table 2 maximum number of patients (70.17\%) were between 21 and 30 years of age. As far as parity is concerned only $12.29 \%$ of patients were primigravida where as $70.71 \%$ patients were multigravida. Previous history of pelvic inflammatory disease was associated among maximum number of cases i.e $50.87 \%$ of total number of cases. Among other risk factors, abortions, previous ectopic pregnancies and history of infertility treatment were associated with $47.36 \%, 14.03 \%$ and $8.77 \%$ of total number of cases respectively. Still there were 14 cases $(24.56 \%)$ where no identifiable risk factors were obtained. Maximum number of patients were from lower and lower middle class socioeconomic status. Common clinical findings that were found in the subjects comprising this study are abdominal distension, abdominal tenderness, cervical motion tenderness, fainting attack, mass in fornices and shock as quoted in Table 3. That also shows various sites that are involved by the ectopic pregnancies in the study group. Tubal ectopic pregnancies were found to be the commonest ones and as far as various sub sites on fallopian tube is concerned it is the ampulla (56.16\%) followed by isthmus $(35.09 \%)$ that were commonly 
involved. Two cornual pregnancies and two ovarian pregnancies were also found in this series. In $85.97 \%$ of patients the amount of hemoperitoneum was found to be more than $500 \mathrm{ml}$.

Table 3: Clinical parameters.

\begin{tabular}{|lll|}
\hline Clinical findings & Frequency & Percent \\
\hline Pain lower abdomen & 49 & 85.96 \\
\hline Bleeding per vaginum & 40 & 70.17 \\
\hline Abdominal tenderness & 49 & 85.96 \\
\hline Fainting attack & 39 & 68.42 \\
\hline Mass in fornices & 32 & 56.14 \\
\hline Cervical motion tenderness & 45 & 78.94 \\
\hline Abdominal distension & 52 & 91.22 \\
\hline Shock & 32 & 56.14 \\
\hline Site & & \\
\hline Ampulla & 32 & 56.16 \\
\hline Isthmus & 20 & 35.09 \\
\hline Fimbria & 1 & 1.75 \\
\hline Cornual/interstitium & 2 & 3.5 \\
\hline Ovarian & 2 & 3.5 \\
\hline Amount of hemoperitoneum & & \\
\hline <500ML & 8 & 14.03 \\
\hline >500ML & 49 & 85.97 \\
\hline
\end{tabular}

\section{DISCUSSION}

Young fertile women with low parity are generally affected by Ectopic pregnancies. In addition to preventing maternal mortality, immediate attention to these symptomatic high risk group and early diagnosis before rupture, could improve their future fertility. ${ }^{7}$ The incidence of ectopic pregnancy has been following a variable trend in different parts of world. Some showing an increasing trend while others showing a falling trend. ${ }^{8-10}$ The current study showed a high incidence rate of ectopic pregnancy i.e. $2.42 \%$ and the incidence of ruptured ectopic pregnancy being $1.99 \%$ in this region of India. Higher prevalence of infectious diseases particularly tuberculosis in this part of India, that could damage the uterine tubes might explain such higher incidence rate of ectopic pregnancy. The incidence rate found in our report is very close to rates reported in studies from other developing countries. ${ }^{7,11-14}$

In developing countries like India there is very low rate of diagnosis of unruptured ectopic pregnancy. In our study only $9.52 \%$ of cases of ectopic pregnancy were diagnosed before they ruptured. This finding is consistent with study reports from other developing countries. ${ }^{11}$ This could be because of two reasons. First, large number of women in rural areas of India are reluctant to use a proper method of contraception. ${ }^{15}$ Second, lack of health education especially in rural areas of India. Therefore, reduction of the present high rates of ruptured ectopic pregnancy and early diagnosis before rupture may be achieved by encouragement of public health education. Maximum cases of ruptured ectopic pregnancies were found in age group of 21- 30 years in our study report as well as in various other studies. ${ }^{16,17}$ This finding is in correspondence with the fact that this is the peak age of sexual activity. studies from different centres are in the view of ampullary pregnancy being the most common type of ectopic pregnancy which is also a finding of our study. ${ }^{18-20}$ As found in our study the preponderance of ectopic pregnancies on the right Fallopian tube is similar to trends all over the world.,21,22 Nordenskjöld and Ahlgren attributed this right-sided preponderance to appendicitis. $^{22}$ For both developed and developing countries it's a common fact that pelvic inflammatory disease is a major risk factor for ectopic pregnancy. ${ }^{23}$ Our study report shows $50.87 \%$ of patients were associated with pelvic inflammatory disease. Other study reports are also having similar findings. ${ }^{12,13,24}$ Other factors like previous history of abortion and history of previous ectopic gestation were also predisposing factors for ectopic pregnancy. ${ }^{14,25,26}$

Most common presenting symptom was pain in abdomen which was seen in $85.96 \%$ cases followed by history of amenorrhea $(80.76 \%)$ were similar with Shetty and Shetty. ${ }^{27}$ Bleeding per vaginum found in $70.17 \%$ cases which is comparable with a study by Yakasai et al. ${ }^{28}$ Classical triad found in $53.84 \%$ cases which is comparable to a study by Singh et al $(60 \%) .{ }^{29}$ In present study, $27(51.92 \%)$ cases presented to the hospital in shock. On clinical examination, it is found that abdominal tenderness present in $85.96 \%$ cases which is consistent with a study carried out by Gaddagi and Chandrashekhar. ${ }^{30}$ Abdominal distension found in 91.22 $\%$ of patients. Cervical motion tenderness noticed in $78.94 \%$ cases which is comparable with Gaddagi and Chandrashekhar. ${ }^{30}$ Adnexal mass felt in $56.14 \%$ cases which is comparable with Gaddagi and Chandrashekhar. ${ }^{30}$ A ruptured ectopic pregnancy may manifest itself with abdominal pain, rebound tenderness, and hemorrhagic/hypovolemic shock. ${ }^{31}$ In our study we found $56.14 \%$ of cases of ruptured ectopic pregnancy were admitted with shock and $85.17 \%$ of cases were found to be with hemoperitoneum of more than $500 \mathrm{ml}$ of blood.

\section{Limitations}

The retrospective design and inability to compare the risk factors with normal pregnancies has rendered these factors into epidemiological samples in our study. The lack of classified treatment protocols for the medical and surgical procedures to be applied to the patients constitutes another limitation.

\section{CONCLUSION}

There is high incidence rate of ectopic pregnancies and the rate of diagnosis is very low before rupture in developing nations as in our scenario. Pelvic inflammatory disease, Poor maternal education, low socioeconomic status and history of subfertilty are the 
risk factors associated with ruptured ectopic pregnancy. There should be more efforts to encourage the level of education not only among common people but also among primary health care provider to improve the rate of diagnosis before the occurrence of rupture. Public awareness programmes should be launched to educate reproductive age group women about the risk factors through electronic media like $\mathrm{TV}$, radio, or newspapers. All these patients should register themselves at a specialist hospital for care of their pregnancy where specialist gynecologists and facilities for diagnosis and treatment of Ectopic pregnancy are available. Finally, more prospective studies are needed in order to perform risk stratification and to define accurate diagnostic criteria for ectopic pregnancy and ruptured ectopic pregnancy.

\section{Funding: No funding sources}

Conflict of interest: None declared

Ethical approval: The study was approved by the Institutional Ethics Committee

\section{REFERENCES}

1. Farquhar CM. Ectopic pregnancy. Lancet. 2005;366:583-91.

2. Jonathan S, Berek. Novaks Gynecology. Lippincott Williams and Wilkins. 2007:602-35.

3. Barnhart KT. Clinical practice: ectopic pregnancy. N Engl J Med. 2009;361:379-87.

4. Leke RJ, Goyaux N, Matsuda T, Thonneau PF. Ectopic pregnancy in Africa: a population-based study. Obstet Gynecol. 2004;103:692-7.

5. Orazulike NC, Konje JC. Diagnosis and management of ectopic pregnancy. Womens Health (Lond Engl. 2013;9:373-85.

6. Senapati S, Barnhart KT. Biomarkers for ectopic pregnancy and pregnancy of unknown location. Fertil Steril. 2013;99:1107-16.

7. Musa J, Daru PH, Mutihir JT, Ujah IA. Ectopic pregnancy in Jos Northern Nigeria: prevalence and impact on subsequent fertility. Niger $\mathrm{J}$ Med. 2009;18:35-8.

8. Rajkhowa M, Glass MR, Rutherford AJ, Balen AH, Sharma V, Cuckle HS. Trends in the incidence of ectopic pregnancy in England and Wales from 1966 to 1996. BJOG. 2000;107:369-74.

9. Aral SO. Sexual behaviour as risk factor for sexually transmitted diseases. In: Germaine A, Holmes KK, Piot P, Wasserheit JN, editors. Reproductive tract infections: global impact and priorities for women's reproductive Health. New York: Plenum Press; 1992:185-91.

10. Boufous S, Quartararo M, Mohsin M and Parker J: Trends in the incidence of ectopic pregnancy in New South Wales between 1990- 1998. Aust NZJ Obstet Gynaecol. 2001;41:436-8.

11. Obed SA. diagnosis of unruptured ectopic is still uncommon in Ghana. Ghana Med J. 2006;40(1):1-7.
12. Anorlu RI, Oluwole A, Abudu OO, Adebajo S. Risk factors for ectopic pregnancy in Lagos, Nigeria. Acta Obstet Gynecol Scand. 2005;84:184-8.

13. Udigwe GO, Umeononihu OS, Mbachu II. Ectopic pregnancy: a 5 year review of cases at Nnamdi Azikiwe Universty Teaching Hospital Nnewi. Niger Med J. 2010;51:160-3.

14. Aboyeji AP, Fawole AA, Ijaiya MA. Trends in ectopic pregnancy in Ilorin, Nigeria. Nigerian J Surg Res. 2002;4:6-11.

15. Ali AA, Rayis, DA, Mamoun M, Adam I. Use of family planning methods in Kassala, Eastern Sudan. BMC Res Notes. 2011;4(1):43.

16. Majhi AK, Roy N, Karmakar KS, Banerjee PK. Ectopic pregnancy: an analysis of 180 cases. J Indian Med Assoc. 2007;105:308-12.

17. Igberase GO, Ebeigbe PN, Igbekoyi OF, Ajufoh BI. Ectopic pregnancy: an 11-year review in a tertiary centre in the Niger Delta. Trop Doct. 2005;35:175-7.

18. Oronsaye AU, Odiase GI. Incidence of ectopic pregnancy in Benin City, Nigeria. Trop Doct. 1981;11:160-3.

19. Swende TZ, Jogo AA. Ruptured tubal pregnancy in Makurdi, north central Nigeria. Niger J Med. 2008; 17:75-7.

20. Sy T, Diallo Y, Toure A, Diallo FB, Balde AA, Hyjazi Y et al. Management of ectopic pregnancy in Conakry, Guinea. Med Trop (Mars). 2009;69:565-8.

21. Gharoro EP, Igbafe AA. Ectopic pregnancy revisited in Benin City, Nigeria: analysis of 152 cases. Acta Obstet Gynecol Scand. 2002;81:1139-43.

22. Nordenskjöld F, Ahlgren M. Risk factors in ectopic pregnancy. Results of a population-based casecontrol study. Acta Obstet Gynecol Scand. 1991;70:575-9.

23. Goyaux N, Leke R, Keita N, Thonneau P. Ectopic pregnancy in African developing countries. Acta Obstet Gynecol Scand. 2003;82:305-12.

24. Amoko DH, Buga GA. Clinical presentation of ectopic pregnancy in Transkei, South Africa. East Afr Med J. 1995;72:770-3.

25. Atrash HK, Strauss LT, Kendrick JS, Skjeldestad FE, Ahn YW. The relation between induced abortion and ectopic pregnancy. Obstet Gynecol. 1997;89:512-8.

26. Skjeldestad FE, Gargiullo PM, Kendrick JS. Multiple induced abortions as risk factor for ectopic pregnancy. A prospective study. Acta Obstet Gynecol Scand. 1997;76:691-6.

27. Shetty S, Shetty A. A clinical study of ectopic pregnancies in a tertiary care hospital of Mangalore, India. Innov J Med Health Sci. 2014;4:305-9.

28. Yakasai IA, Abdullahi J, Abubakar IS. Management of ectopic pregnancy in Aminu Kano teaching hospital Kano Nigeria: A 3-year. Glob Adv Res J Med Med Sci. 2012;1:181-5.

29. Singh S, Mahendra G, Vijayalakshmi S, Pukale RS. Clinical study of ectopic pregnancy in a rural setup: A two year survey. Natl J Med Res. 2014;4:37-9. 
30. Gaddagi RA, Chandrashekhar AP. A clinical study of ectopic pregnancy. J Clin Diagn Res. 2012;6:8679.

31. Orazulike NC, Konje JC. Diagnosis and management of ectopic pregnancy. Womens Health (Lond Engl). 2013;9:373-85.
Cite this article as: Panda SR, Rani A, Meena M. Clinicosociodemographic profile of ruptured ectopic pregnancies at a tertiary care centre. Int J Reprod Contracept Obstet Gynecol 2017;6:1885-9. 